$1985,34,4$

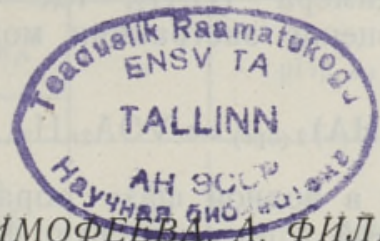

удіК $546.881 .4: 542.61$

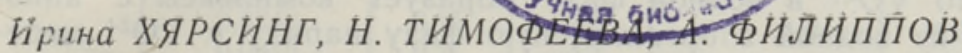

\title{
ВЛИЯНИЕ СУЛЬФИТА НАТРИЯ НА ЭКСТРАКЦИЮ ВАНАДИЯ(IV) ДИ-2-ЭТИЛГЕКСИЛФОСФОРНОЙ КИСЛОТОЙ ИЗ СЕРНОКИСЛЫХ РАСТВОРОВ
}

\author{
(Представил О. Эйзен)
}

При кислотном выщелачивании некоторых руд [1] и аргиллитов [2] в присутствии восстановителя $\left(\mathrm{SO}_{2}, \mathrm{Fe}\right.$-стружка) получаемые растворы содержат ванадий преимущественно в четырехвалентной форме. Известно, что ванадий(IV) экстрагируется ди-2-этилгексилфосфорной кислотой (Д2ЭГФК) [ $\left.{ }^{3-6}\right]$ из кислых растворов лучше, чем ванадий (V) [7]. Для перевода ванадия в четырехвалентную форму можно использовать сульфит натрия [8, 9].

Цель настоящей работы - изучение экстракции ванадия(IV) из сернокислых растворов с использованием Д2ЭГФК в н-гексане в условиях варьирования концентраций сульфита натрия, Д2ЭГФК и $\mathrm{pH}$ растворов.

\section{Әкспериментальная часть}

Растворы ванадия (IV) ( $\mathrm{C}_{\mathrm{v}(\mathrm{IV})}^{\text {ncx }}=0,04$ моль/л) в разбавленной серной кислоте «хч» готовили из сульфата ванадила «чда». Необходимый солевой фон в этих растворах создавали добавлением соответствующих навесок сульфита натрия марки «чда». Для предотвращения окисления ванадия (IV) и сульфита натрия кислородом воздуха колбы перед приготовлением растворов продували аргоном. Концентрацию ванадия в водных растворах определяли титрованием солью Мора в присутствии фенилантраниловой кислоты в качестве индикатора [10], предварительно окислив ванадий(IV) и сульфит натрия перманганатом калия. Концентрацию сульфита в водной фазе определяли иодометрически. Содержание ванадия и сульфита в органической фазе рассчитывали по разности их концентраций в водном растворе до экстракции и после нее. Концентрацию водородных ионов определяли на $\mathrm{pH}$-метре $\mathrm{pH}-340$.

Экстрагент Д2ЭГФК предварительно очищали от моно-2-этилгексилфосфорной кислоты, обрабатывая его раствором карбоната натрия и затем отмывая разбавленной серной кислотой и водой [1']. В каче-

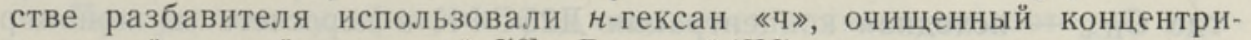
рованной серной кислотой [12]. Ванадий(IV) экстрагировали растворами Д2ЭГФК $(0,1-0,3$ моль/л, в пересчете на мономер) в $\boldsymbol{H}$-гексане при соотношении органической и водной фаз $V_{\text {орг }}: V_{\text {водн }}=1: 1$ в интервале $\mathrm{pH}$ исходных растворов $\left(\mathrm{pH}_{\text {nсх }}\right)$ от 0,2 до 3,5 , используя термостатированные делительные воронки. Температура экстракции $25 \pm 0,5^{\circ} \mathrm{C}$. Делительные воронки предварительно продували аргоном. Перемешивание фаз осуществляли путем встряхивания делительных воронок на механической качалке в течение 15 мин. 


\section{Результаты и об̈суждение}

Экетракция ванадия(IV) раствором Д2ЭГФК сопровождается выделе нием ионов водорода $[3,4,6,13]$. В связи с тем, что в $H$-гексане Д2ЭГФК существует в виде димера $(\mathrm{HA})_{2}$, где А - анион Д2ЭГФК $\left(\mathrm{C}_{8} \mathrm{H}_{17} \mathrm{O}\right)_{2} \mathrm{PO}_{4}\left[{ }^{14}\right]$, уравнение экстракции можно представить следующим образом:

$$
\mathrm{VO}^{2+}{ }_{(\text {водн) }}+n(\mathrm{HA})_{2 \text { (орг) }} \rightleftarrows \mathrm{VOA}_{2 n} \mathrm{H}_{2 n-2} \text { (орг) }+2 \mathrm{H}^{+}{ }_{(\text {водн) }} .
$$

Известно, что $\mathrm{VO}^{2+}$ в водной фазе образует комплексы с анионами [ ${ }^{15}$. Если из водной в органическую фазу наряду с $\mathrm{VO}^{2+}$ переходят катионы $\mathrm{VO} X^{+}\left(X-\mathrm{HSO}_{4}^{-}, \mathrm{HSO}_{3}^{-}\right)$, тогда

$$
\mathrm{VOX}_{(\text {(водн) }}+n(\mathrm{HA})_{2} \text { (орг) } \rightleftarrows \mathrm{VOA}_{2 n} \mathrm{H}_{2 n-1} X_{\text {(орг) }}+\mathrm{H}^{+}{ }_{\text {(водн) }} .
$$

При переходе в органическую фазу нейтральных частиц ионы водорода в водную фазу не переходят:

$$
\begin{aligned}
\operatorname{VOX}_{2 \text { (водн) }}+n(\mathrm{HA})_{2(\text { орг) }} & \rightleftarrows \mathrm{VOA}_{2 n} \mathrm{H}_{2 n} X_{2}, \\
\operatorname{VOY}_{\text {(водн) }}+n(\mathrm{HA})_{2(\text { (орr })} & \rightleftarrows \mathrm{VOA}_{2 n} \mathrm{H}_{2 n} Y,
\end{aligned}
$$

где $Y-\mathrm{SO}_{4}^{2-}, \mathrm{SO}_{3}^{2-}$.

При малых концентрациях ванадия в растворе, когда изменением коэффициентов активности в процессе экстракции можно пренебречь, общая константа равновесия экстракции $K$, выведенная на основе уравнений экстракции I-IV, может быть записана в концентрационной форме:

$$
K=C_{\mathbf{V}(\mathrm{IV})}^{\mathrm{opr}}\left[\mathrm{H}^{+}\right]^{m} / C_{\mathbf{V}(\mathrm{IV})}^{\text {водн }}\left[(\mathrm{HA})_{2}\right]^{n},
$$

где $C_{\mathbf{V}(\mathrm{IV})}^{\mathrm{opr}}$ и $C_{\mathbf{V}(\mathrm{IV})}^{\text {водн }}-$ общие концентрации ванадия в органической и водной фазах соответственно.

Коэффициент распределения ванадия (IV)

$$
\alpha=C_{\mathbf{V}(\mathrm{IV})}^{\mathrm{opr}} / C_{\mathbf{V}(\mathrm{IV})}^{\text {води }}
$$

связан с общей константой равновесия экстракции следующим соотношением:

$$
\alpha=K\left[(\mathrm{HA})_{2}\right]^{n} /\left[\mathrm{H}^{+}\right]^{m}
$$

или в логарифмической форме:

$$
\lg \alpha=\lg K+m p \mathrm{H}+n \lg \left[(\mathrm{HA})_{2}\right] .
$$

Концентрацию свободного димера Д2ЭГФК можно рассчитать из выражения

$$
\left[(\mathrm{HA})_{2}\right]=[\mathrm{HA}] / 2=C_{\mathrm{HA}} / 2-n C_{\mathrm{V}(\mathrm{IV})}^{\mathrm{opr}} ;
$$

где $C_{\mathrm{HA}}-$ исходная концентрация Д2ЭГФК в пересчете на мономер.

Есть данные, что в отсутствии сульфита натрия значение $m=2$, a значение $n$ изменяется от 1 до 2 в зависимости от концентрации экстрагента ${ }^{16}{ }^{6}$. Сведения о величинах $m$ и $n$ при экстракции в присутствии сульфита натрия в литературе отсутствуют и, кроме того, возникает вопрос о возможности перехода в органическую фазу сульфита, связанного с $\mathrm{VO}^{2+}$.

Величину $n$ вычисляли методом итерации по прямолинейной зависимости $\lg \alpha$ от $\lg \left[(\mathrm{HA})_{2}\right]$ при постоянном значении $\mathrm{pH}$ равновесных 
Значёнияя $\boldsymbol{n}$ в уравнениях экстракции в присутствии и отсутствии сульфита натрия $(\underset{\mathrm{V}(\mathrm{IV})}{\mathrm{HCx}}=0,04$ моль/л)

\begin{tabular}{|c|c|c|c|c|c|c|}
\hline$C_{\mathrm{Na}_{2} \mathrm{SO}_{3}}$ & $C_{\mathrm{V}(\mathrm{IV})}^{\mathrm{opr}}$ & $C_{\mathrm{HA}}$ & $\alpha$ & $\mathrm{pH}_{\mathrm{panh}}$ & $n$ & $S_{n}$ \\
\hline \multicolumn{3}{|c|}{ моль/л } & & & & \\
\hline 0,3 & $\begin{array}{l}0,0241 \\
0,0248 \\
0,0315 \\
0,0342\end{array}$ & $\begin{array}{l}0,1 \\
0,15 \\
0,2 \\
0,3\end{array}$ & $\begin{array}{l}1,6 \\
2,6 \\
4,1 \\
6,9\end{array}$ & $1,6-1,8$ & 1,0 & $3,5 \cdot 10^{-2}$ \\
\hline- & $\begin{array}{l}0,0318 \\
0,0358 \\
0,0369\end{array}$ & $\begin{array}{l}0,1 \\
0,15 \\
0,20\end{array}$ & $\begin{array}{r}4,1 \\
9,5 \\
14,3\end{array}$ & 2,0 & 1,0 & $6,1 \cdot 10^{-2}$ \\
\hline 0,3 & $\begin{array}{l}0,0171 \\
0,0234 \\
0,0246 \\
0,0300\end{array}$ & $\begin{array}{l}0,1 \\
0,15 \\
0,2 \\
0,3\end{array}$ & $\begin{array}{l}0,7 \\
1,5 \\
1,7 \\
3,3\end{array}$ & 1,5 & 1,1 & $1,8 \cdot 10^{-2}$ \\
\hline- & $\begin{array}{l}0,0290 \\
0,0333 \\
0,0351 \\
0,0365\end{array}$ & $\begin{array}{l}0,1 \\
0,15 \\
0,2 \\
0,3\end{array}$ & $\begin{array}{r}3,2 \\
5,7 \\
8,6 \\
13,5\end{array}$ & $1,4-1,5$ & 0,9 & $1,5 \cdot 10^{-2}$ \\
\hline
\end{tabular}

растворов ( $\left.\mathrm{pH}_{\text {равн }}\right)$ (4) с учетом расхода Д2ЭГФК на комплексообразование с ванадием(IV) (5). Рассчитанное значение $n$ (тангенс угла наклона зависимости $\lg \alpha$ от $\left.\lg \left[(\mathrm{HA})_{2}\right]\right)$ (табл. 1) в условиях опытов в среднем равно единице при среднеквадратичном отклонении $\left(S_{n}\right)$ порядка $10^{-2}$ и не зависит существенно от присутствия сульфита натрия.

Значение $m$ определяли по графикам зависимости $\lg \alpha-\lg \left[(\mathrm{HA})_{2}\right]$ от $\mathrm{pH}_{\text {равн. }}$ Из рис. 1 видно, что эти зависимости представляют собой прямые с тангенсом угла наклона $m=2$. Следовательно, при малых концентрациях ванадия (IV) в присутствии сульфита натрия в условиях опытов экстракция ванадия(IV) в основном проходит по уравнению

$$
\mathrm{VO}^{2+}{ }_{(\text {водн) }}+(\mathrm{HA})_{2 \text { (орг) }} \rightleftarrows \mathrm{VOA}_{2} \text { (орг) }+2 \mathrm{H}^{+}{ }_{(\text {водн })},
$$

а уравнение, связывающее коэффициент распределения с константой экстракции, имеет вид

$$
\lg \alpha=\lg K+2 p \mathrm{H}+\lg \left[(\mathrm{HA})_{2}\right] .
$$

Значения $K$, вычисленные по уравнению (6), приведены в табл. 2. Доверительная вероятность значений $K$, вычисленная с использованием коэффициентов Стьюдента, была не менее 0,85 . Величина $K$ уменьшается в присутствии сульфита, что, очевидно, обусловлено конкурирующим влиянием комплексообразования ванадия(IV) с ионами сульфита в водной фазе.

Присутствие сульфита натрия оказывает влияние на изотермы экстракции ванадия (IV), которые получены путем варьирования соотношения объемов органической и водной фаз (рис. 2). В насыщенной органической фазе соотношение молей Д2ЭГФК (в пересчете на мономер) и ванадия(IV) равно 2:1, что согласуется с рассчитанным значением $n$ (табл. 1).

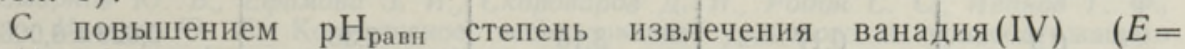
$=\alpha /(\alpha+1))$ значительно растет (рис. $3, a)$, достигая максимального значения в присутствии сульфита натрия при $\mathrm{pH}_{\text {равн }} 2,6$, а извлечение 


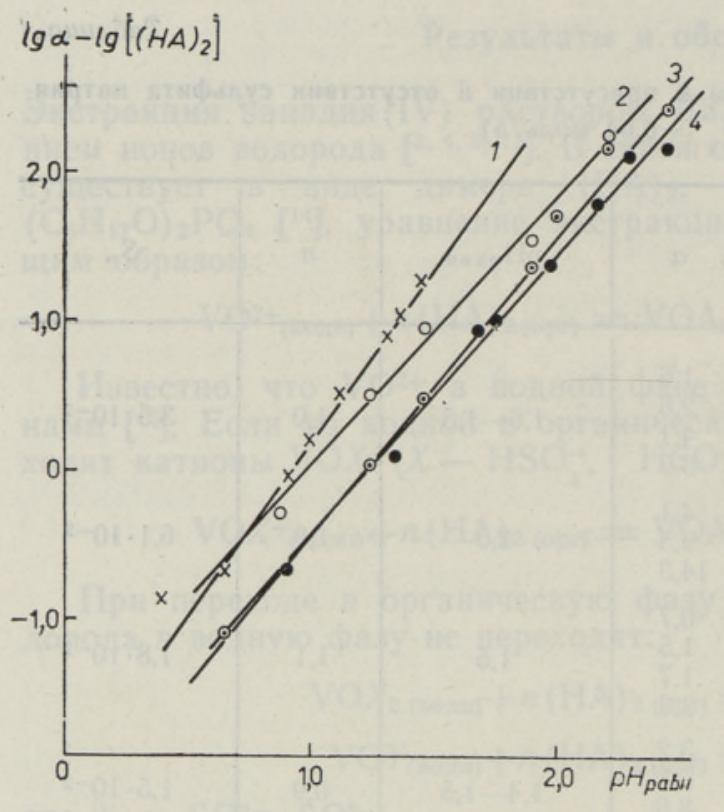

Рис. 1.

Рис. 2 ,

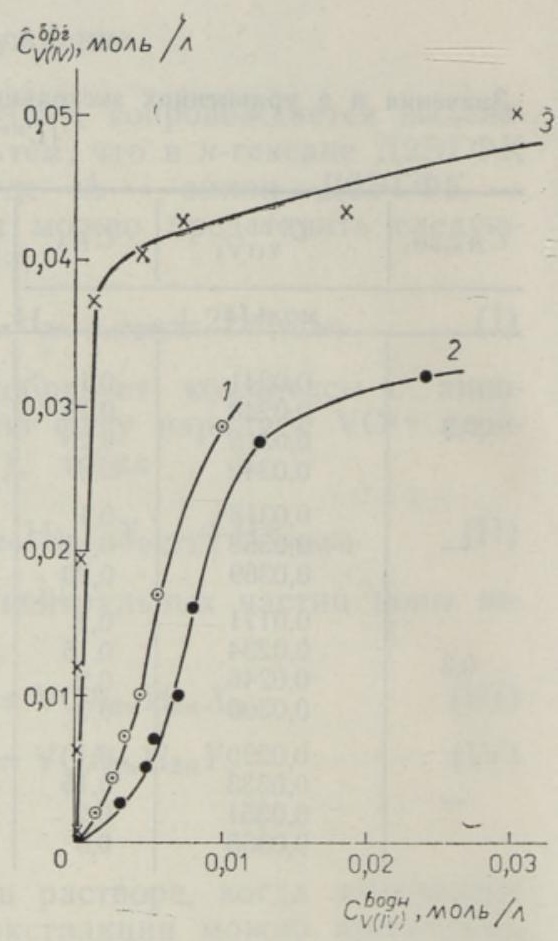

Рис. 1. Зависимость $\lg \alpha-\lg \left[(\mathrm{HA})_{2}\right]$ от $\mathrm{pH}_{\text {равн. }} \underset{\mathbf{V}(\mathrm{IV})}{\mathrm{ucx}}=0,04$ моль/л; $C_{\text {Н } \mathrm{A}}=0,1$ моль $/ л$. 1 - без сульфита натрия, $m=2,2 \pm 0,1 ; 2-C_{\mathrm{Na}_{2} \mathrm{SO}_{3}=0,1}$ моль $/ л, \quad m=1,9 \pm 0,1 ; 3-$

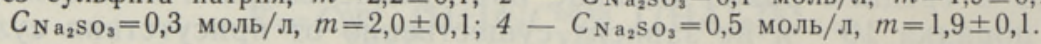

Рис. 2. Изотермы экстракции ванадия (IV) раствором Д2ЭГФК в н-гексане. $C_{\text {HА }}=$

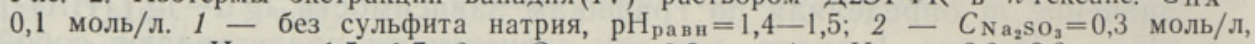

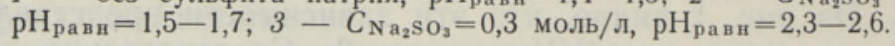

сульфит-иона в органическую фазу уменьшается. Небольшое увеличение экстракции сульфита в присутствии ванадия(IV), по-видимому, обусловлено экстракцией последнего в виде комплекса с сульфитом. Возможно также, что экстрагируемая органической фазой $\mathrm{H}_{2} \mathrm{SO}_{3}$ (или $\mathrm{SO}_{2}$ ) частично ассоцируется с $\mathrm{VOA}_{2}$, за счет чего несколько смещается равновесие ее экстракции.

Из рис. 3, б видно, что ванадий (IV) экстрагируется с высокой степенью извлечения при $\mathrm{pH}_{\text {исх }} 2-3,5$. При концентрации сульфита нат-

Таблица 2

$$
\begin{gathered}
\text { Константы экстракции ванадия(IV) из сернокислых растворов } \\
\text { раствором Д2ЭГФК в } \boldsymbol{H} \text {-гексане } \\
\left(C_{\mathrm{V}(\mathrm{IV})}^{\text {исх }}=0,04 \mathrm{моль} / л ; C_{\mathrm{HA}}=0,1 \mathrm{моль} / л\right)
\end{gathered}
$$

\begin{tabular}{|c|c|c|c|c|}
\hline $\begin{array}{c}C_{\mathrm{Na}_{2} \mathrm{SO}_{3}} \\
\text { моль/л }\end{array}$ & $\begin{array}{l}C_{\mathrm{so}_{4}^{2-},} \\
\text { г-нон/л }\end{array}$ & $\mathrm{pH}_{\mathrm{ni} \mathrm{cx}}$ & $\mathrm{pH}_{\mathrm{paвн}}$ & $K$ \\
\hline $\begin{array}{l}0,3 \\
0,3 \\
-\end{array}$ & $\begin{array}{l}0,17 \\
0,24 \\
0,04\end{array}$ & $\begin{array}{l}3,10 \\
1,74 \\
2,91\end{array}$ & $\begin{array}{l}2,30 \\
1,50 \\
1,40\end{array}$ & $\begin{array}{c}0,028 \pm 0,006 \\
0,031 \pm 0,004 \\
0,07 \pm 0,01\end{array}$ \\
\hline
\end{tabular}



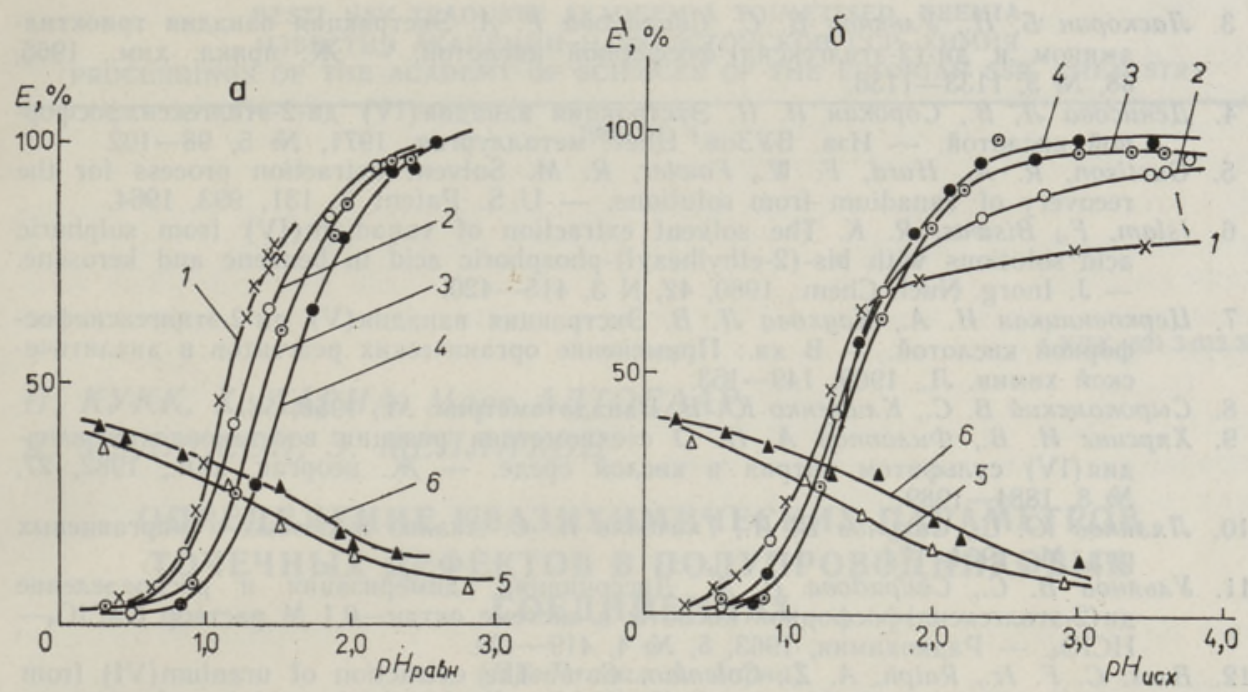

Рис. 3. Зависимость степени извлечения ванадия(IV) $\left(C_{\mathbf{v}(\mathrm{IV})}^{\text {ucx }}=0,04\right.$ моль/л) и

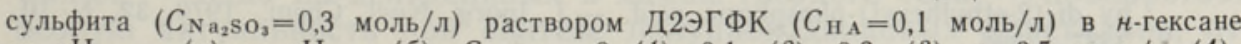
от $\mathrm{pH}_{\text {равн }}(a)$ и $\mathrm{pH}_{\text {исх }}$ (б). $C_{\mathrm{Na}_{2} \mathrm{SO}_{3}=0}$ (1), 0,1 (2), 0,3 (3) и 0,5 моль/л (4);

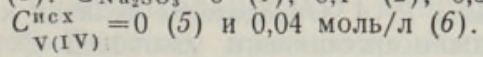

рия 0,3 и 0,5 моль/л степень извлечения ванадия(IV) за одну ступень экстракции при $\mathrm{pH}_{\text {нсх }}=3,0$ и $V_{\text {орг }}: V_{\text {водн }}=1: 1$ достигает 96,0 и $98,5 \%$ соответственно.

Известно, что ванадий (IV) окисляется на воздухе при $\mathrm{pH}_{\text {исх }}>2\left[{ }^{17}\right]$. Поэтому для проведения экстракции в вышеуказанных условиях необходимо создать инертную или воєстановительную среду. Добавление сульфита натрия к раствору ванадия(IV) предотвращает его окисление на воздухе, повышает $\mathrm{pH}_{\text {равн }}$ раствора, что способствует извлечению ванадия.

\section{Выводы}

1. Экстракция ванадия(IV) раствором Д2ЭГФК в $н$-гексане из сернокислых растворов в присутствии сульфита натрия в основном описывается уравнением

$$
\mathrm{VO}^{2+}{ }_{(\text {водн })}+(\mathrm{HA})_{2(\text { орг })} \rightleftarrows \mathrm{VOA}_{2(\text { орг })}+2 \mathrm{H}^{+}{ }_{(\text {водн) }} .
$$

Константа экстракции ванадия(IV) уменьшается в присутствии сульфита натрия, что объясняется комплексообразованием ванадия(IV) с сульфит-ионами в водной фазе.

2. Добавка сульфита натрия к раствору ванадия(IV) способствует экстракции последнего за счет повышения $\mathrm{pH}$ водной фазы и предотвращает окисление ванадия (IV).

\section{ЛИТЕРАТ У Р А}

1. Смирнов Ю. В., Ефимова З. И., Скороваров Д. И., Родин С. С., Иванов Г. Ф., Нсаков Ю. $Г$. Комплексное использование уранового и урансодержащего сырья. - Атом. техн. за рубежом, 1976, № 1, 14-27.

2. Палвадре $P$., Клээмейер $T$. Выщелачиваемость некоторых тяжелых металлов из аргиллитов. - Изв. АН ЭССР. Хим., 1982, 31, № 4, 243-248. 
3. Ласкорин Б. Н., Ульянов В. С., Свиридова Р. А. Экстракция ванадия триоктиламином и ди-(2-этилгексил)-фосфорной кислотой. - Ж. прнкл. хим., 1965 38, № 5, 1133-1136.

4. Денисова Л. В., Сорокин Н. П. Экстракция ванадия(IV) ди-2-этилгексилфосфорной кислотой. - Изв. ВУЗов. Цвет. металлургия, 1971, № 5, 98-102

5. Gustison, R. A., Hurd, F. W., Fowler, R. M. Solvent extraction process for the recovery of vanadium from solutions. - U.S. Patent 3, 131, 993, 1964.

6. Islam, F., Biswas, R. K. The solvent extraction of vanadium(IV) from sulphuric acid solutions with bis-(2-ethylhexyl)-phosphoric acid in benzene and kerosene. - J. Inorg. Nucl. Chem., 1980, 42, N 3, 415-420.

7. Церковницкая Н. А., Каухова Л. В. Экстракция ванадия (V) ди-2-этилгексилфосфорной кислотой. - В кн.: Применение органических реагентов в аналитнческой химин. Л., $1969,149-153$.

8. Сырокомский В. С., Клименко Ю. В. Ванадатометрия. М., 1950, 58.

9. Хярсинг И. В., Филиппов А. П. О стехиометрии реакции восстановлення ванадия(IV) сульфитом натрия в кислой среде. - Ж. неорган. хим., 1982, 27, № $8,1884-1989$.

10. Ляликов Ю. С., Сакунов В. И., Ткаченко Н. С. Анализ железных и марганцевых руд. М., 1954, 174.

11. Ульянов B. C., Свиридова P. A. Диссоциация, димеризация и распределение ди (2-этилгексил) фосфорной кислоты в системе октан-0,1 M раствор $\mathrm{NaClO}_{4}-$ $\mathrm{HClO}_{4}$. - Радиохимия, 1963, 5, № 4, 419-424.

12. Baes, C. F. Jr., Ralph, A. Z., Coleman, C. F. The extraction of uranium(VI) from acid perchlorate solutions by di-(2-ethyl-hexyl)-phosphoric acid in $n$-hexane. J. Phys. Chem., 1958, 62, N 2, 129-136.

13. Sato, T., Takeda, T. The extraction of vanadium(IV) from sulphuric acid solutions by di-(2-ethylhexyl)-phosphoric acid. - J. Inorg. Nucl. Chem., 1970, 32, N 10, $3387-3396$.

14. Ульянов В. С., Свиридова Р. А. Определение величин констант димеризацин, распределения, кислотной диссоциации диалкилфосфорных кислот и констант ассоциации с трибутилфосфатом и трноктилфосфиноксидом в различных разбавителях. - Радиохимия, 1970, 12, № 1, 47-64.

15. Ивакин А. А., Воронова Э. М. Спектрофотометрическое исследование сернокислых комплексов ванадия(IV). - Ж. неорган. хим., 1973, 18, № 7, 1809-1812.

16. Козлов В. А., Кунаев А. М., Батракова Л. Х. Исследование механизма экстракции ванадия (IV) ди-2-этилгексилфосфорной кислотой. - Комплексное использование минерального сырья (Алма-Ата), 1980, № 12, 19-23.

17. Шарло $Г$. Методы аналитической химин. Количественный анализ неорганических соединений. Ч. 2. М., 1969, 726.
Ннститут химии
Академии наук Эстонской ССР
Поступила в редакцию

Ннститут физической химии

Академии наук Украинской ССР

Irina HARSING, N. TIMOFEJEVA, A. FILIPPOV

\title{
NAATRIUMSULFITI MOJU VANAADIUM(IV) EKSTRAKTSIOONILE DI-2-ETUULHEKSUOLFOSFORHAPPEGA VÄVELHAPPELISTEST LAHUSTEST
}

Vanaadium(IV) ekstraheerub di-2-etüülheksüülfosforhappega $n$-heksaanis väävelhappelistest lahustest naatriumsulfiti manulusel kōrge ekstraktsiooniastmega lähtelahuste $\mathrm{pH}$ $2-3,5$ juures. On tuletatud vanaadium(IV) ekstraktsiooni võrrand.

Irina HARSING, N. TIMOFEYEVA, A. FILIPPOV

\begin{abstract}
THE INFLUENCE OF SODIUM SULPHITE ON THE EXTRACTION OF VANADIUM(IV) WITH DI-(2-ETHYLHEXYL)-PHOSPHORIC ACID FROM SULPHURIC ACID SOLUTIONS
\end{abstract}

Vanadium(IV) was extracted with a solution of di-(2-ethylhexyl)-phosphoric acid in $n$-hexane from sulphuric acid solutions in the presence of sodium sulphite ( $\mathrm{pH} 2.0-$ 3.5) with a high distribution coefficient. The extraction equation has been deduced. 